\title{
IMPACT STRENGTH OF AN EXPERIMENTAL POLYURETHANE- BASED POLYMER
}

Z. Radzi, N.H. Abu Kasim, N.A. Yahya, S.N. Gan, N.M. Daud, L. Saffai, F.A. Fadhel. Impact strength of an experimental polyurethane-based polymer. Annal Dent Univ Malaya 2007; 14: 46-51.

\section{ABSTRACT}

The impact strength of a newly developed experimental polyurethane-based polymer which is derived from palm oil (Experimental PU) was compared with denture polymers; heat-cured and self cured polymethyl methacrylate (PMMA) and Eclipse $^{\circledR}$, light-activated urethane dimethacrylate prosthetic resin system. Ten specimens were prepared using heat-cured PMMA (Meliodent ${ }^{\circledR}$ Heat Cure, Heraeus Kulzer, Germany), self cured PMMA (Meliodent ${ }^{\circledR}$ Rapid Repair, Heraeus Kulzer, Germany), Eclipse ${ }^{\circledR}$ baseplate resin (Dentsply, USA) and Experimental PU material.

Specimens were prepared following manufacturer's instructions except for the Experimental PU material where it was prepared in bulk and sectioned to the desired dimension, $64 \times 6 \times 4 \mathrm{~mm}$. A ' $\mathrm{V}$ ' notch of approximately $0.8 \mathrm{~mm}$ in depth was machine cut across the $6 \mathrm{~mm}$ width. Prior to the Charpy type impact test, specimens were soaked in a water bath for 50 hours at $37^{\circ} \mathrm{C}$.

Eclipse $^{\circledR}$ baseplate resin showed the highest impact strength $\left(2.73 \mathrm{~kJ} / \mathrm{m}^{2} \pm 0.54\right)$ followed by Meliodent ${ }^{\circledR}$ Rapid Repair $\left(2.50 \mathrm{~kJ} / \mathrm{m}^{2} \pm 0.65\right)$, Meliodent ${ }^{\circledR}$ Heat Cure $\left(1.96 \mathrm{~kJ} / \mathrm{m}^{2} \pm 0.42\right)$ and Experimental PU $\left(1.04 \mathrm{~kJ} / \mathrm{m}^{2} \pm 0.29\right)$. One-way ANOVA showed significant interaction between materials $(\mathrm{p}<.05)$ and Tukey HSD revealed that Experimental PU exhibited significantly lower impact strength compared to other materials. Meliodent ${ }^{\circledR}$ Rapid Repair was not significantly different from Meliodent ${ }^{\circledR}$ Heat Cure and Eclipse ${ }^{\circledR}$ baseplate resin.

It can be concluded that the Experimental PU exhibited the lowest impact strength while Eclipse ${ }^{\circledR}$ baseplate resin the highest.

Key words: impact strength; denture based material; dental polymer

\section{INTRODUCTION}

Denture is commonly used to replace missing teeth and the denture base must be strong enough to allow the prosthesis to withstand functional, parafunctional masticatory forces and shock induced fracture possibly due to patient abuse. Denture may
Original Article

Z. Radzi ${ }^{1}$, N.H. Abu Kasim², N.A. Yahya², S.N. Gan ${ }^{3}$, N.M. Daud ${ }^{4}$, L. Saffai ${ }^{4}$, F.A. Fadhel ${ }^{2}$

${ }^{1}$ Department of Children's Dentistry \& Orthodontics Faculty of Dentistry, University of Malaya 50603, Kuala Lumpur.

${ }^{2}$ Department of Conservative Dentistry Faculty of Dentistry, University of Malaya 50603, Kuala Lumpur.

${ }^{3}$ Department of Chemistry, Faculty of Science, University of Malaya, 50603, Kuala Lumpur.

${ }^{4}$ Dental Officer

Ministry of Health Malaysia

Corresponding author: Dr Zamri Radzi

also fracture due to weakened flanges around frenal notches and excessively thin areas. A denture base that is too thick can cause problems such as gagging or dislodgement of the denture when the patient opens wide. Interference at the coronoid process during movement of the mandible can also occur if the maxillary denture is too thick at the disto-buccal region. While the clinician has to minimize the thickness of the denture base for patients' comfort and acceptance, it is also important that resin of high impact strength be used for denture fabrication. These factors have led manufacturers and researchers to develop new polymers to be used as base material for dentures or even other removable appliances.

Historically materials such as bone, wood, ivory, and vulcanized rubber have been used as denture bases and currently polymethyl methacrylate (PMMA) is the preferred material based on its low cost, relative easy manipulation and the utilization of simple processing equipment (1-4). Denture base made from PMMA has good dimensional stability, sufficient strength (5-9) and it also matches the appearance of normal soft tissues. However, the residual monomer in PMMA has the potential to cause irritation and allergic reaction to the oral mucosa (10-13).

Although PMMA is well received there is a need for development of new polymers to address the problems such as fatigue failure, impact failure, residual monomer, porosity and water sorption (59 ). These problems has led to many efforts to improve PMMA's mechanical properties. Several 
studies had been done to improve this property by adding fibers such as carbon fibers, glass fibers and aramid fibers (14-18).

Several types of polymers have been developed to substitute PMMA as denture base materials including nylon, light-activated urethane, dimethylmethacrylate, rubber reinforced PMMA and polyurethane. Studies have shown that polyurethanebased polymer is very promising when used in medical application as it is tough and resistant to abrasion, tear and fatigue (19). Gan (20) patented a process of producing polyol and polyurethane adhesives from palm-oil. This leads to the development of an experimental palm-oil based polyurethane which may be used as a polymer in the fabrication of dentures. This idea also originated from its wide used in medical and industrial field (21). In medical field, polyurethane has been used as heparin coatings, hollow fibers devices, probe covers, catheters, wound dressings, gloves and condoms. Polyurethane has also been used in artificial heart and vascular prostheses and also pacemakers lead insulators (21).

Polyurethanes are segmented polymers that have both soft and hard segment. Thus it provides both flexibility and toughness characteristics. Polyurethanes are chemically bonded to each other, so there is lack of extractable or residual chemicals that may cause allergic reaction $(19,21)$. Urethanebased polymer has been used for clinical dentistry. Their applications include resin for dental composite, bonding agents and as base material for dentures.

Dentures are susceptible to high impact forces when accidentally dropped by the patients (22). Thus the ability of a material to withstand the presences of notches and propagation of crack is an important factor affecting the denture performance. Impact tests, either Charpy or Izod have been used to simulate fractures $(23,25)$ where the energy absorbed by the specimens is quantified until it fractures. Since the palm oil-based polyurethane polymer is still at an experimental stage it was felt that an evaluation of its impact strength may facilitate its further refinement. Therefore, the purpose of this study was to evaluate the impact strength of this newly developed experimental polyurethane-based polymer.

\section{MATERIALS AND METHOD}

Bar specimens of approximately $65 \times 7 \times 5 \mathrm{~mm}$ in dimension were made of Eclipse ${ }^{\circledR}$ baseplate resin (Dentsply, USA), Meliodent ${ }^{\circledR}$ Heat Cure denture base material (Heraus Kultzer, Germany), Meliodent ${ }^{\circledR}$ Rapid Repair (Heraus Kultzer, Germany) and the newly developed experimental polyurethane-based polymer (Experimental PU). The manufacturers' instructions for mixing and processing were followed for the three commercial materials used in this study (Table 1). The Experimental PU material was prepared by mixing polyol extracted from palm oil termed as Polyol FA35 (patent applied) and isocyanate as the catalyst at a ratio of 1:180. It was then poured in a tray and allowed to set at room temperature and form a sheet of $5 \mathrm{~mm}$ thickness. It was then sectioned to the desired dimension, $64 \times 6 \times 4 \mathrm{~mm}$.

Ten specimens from each material were fabricated giving a total of 40 specimens for the impact test. All specimens were wet-ground using 600 grit silicon carbide grinding paper mounted on a Metaserv $^{\circledR} 2000$ (Buehler, UK) grinder polishing machine at 1200 r.p.m. The finished specimens were approximately $64 \mathrm{~mm}$ in length, $6 \mathrm{~mm}$ wide and $4 \mathrm{~mm}$ in height as specified by ISO (1567: 1999) for denture base polymer.

A ' $V$ ' notch was made by machining to a depth of approximately $0.8 \mathrm{~mm}$ across the $6 \mathrm{~mm}$ width leaving an effective depth of $3.2 \mathrm{~mm}$ below the notch on each specimen. Specimens were then soaked in a water bath for $48 \pm 2$ hours at $37^{\circ} \mathrm{C}$ prior to impact testing.

Table 1. Polymers included in this study

\begin{tabular}{|c|c|c|c|c|c|}
\hline Brand Name & $\begin{array}{l}\text { Polymer:monomer } \\
\text { ratio }\end{array}$ & $\begin{array}{c}\text { Batch No. } \\
\text { (polymer/monomer) }\end{array}$ & Manufacturer & Description & $\begin{array}{l}\text { Polymerisation } \\
\text { Procedure }\end{array}$ \\
\hline $\begin{array}{l}\text { Meliodent Heat } \\
\text { Cure }\end{array}$ & $34 \mathrm{~g}: 17 \mathrm{~mL}$ & $64713213 / 64713308$ & $\begin{array}{l}\text { Heraeus Kulzer, } \\
\text { Germany }\end{array}$ & $\begin{array}{c}\text { Heat } \\
\text { polymerised }\end{array}$ & $\begin{array}{c}7 \mathrm{hrs} \text { at } 70^{\circ} \mathrm{C} \text { and } \\
1 \mathrm{hr} \text { at } 100^{\circ} \mathrm{C}\end{array}$ \\
\hline $\begin{array}{l}\text { Meliodent Rapid } \\
\text { Repair }\end{array}$ & $17 \mathrm{~g}: 5 \mathrm{~mL}$ & $64713398 / 64713415$ & $\begin{array}{l}\text { Heraeus Kulzer, } \\
\text { Germany }\end{array}$ & $\begin{array}{c}\text { Self } \\
\text { polymerised }\end{array}$ & $\begin{array}{l}10 \text { mins in water } \\
\text { at } 55^{\circ} \mathrm{C} \text { under } \\
2 \text { bar pressure }\end{array}$ \\
\hline $\begin{array}{l}\text { Eclipse Prosthetic } \\
\text { Resin System }\end{array}$ & $\begin{array}{c}\text { Baseplate supplied } \\
\text { as pre-packed } \\
\text { material }\end{array}$ & 030822 & $\begin{array}{l}\text { Dentsply, } \\
\text { Trubyte, USA }\end{array}$ & Light-activated & $\begin{array}{c}\text { Visible blue } \\
\text { light }\end{array}$ \\
\hline Experimental PU & $1: 180$ & - & $\begin{array}{c}\text { University of Malaya, } \\
\text { Kuala Lumpur, } \\
\text { Malaysia }\end{array}$ & $\begin{array}{l}\text { Chemically- } \\
\text { activated }\end{array}$ & $\begin{array}{l}\text { Polymerised at } \\
\text { room temperature }\end{array}$ \\
\hline
\end{tabular}


Impact strength was determined using a Charpytype pendulum impact tester (Ray $\operatorname{Ran}^{\circledR}$ Universal Pendulum Impact System, UK) at room temperature. One-way analysis of variance (ANOVA) and post-hoc Tukey HSD, SPSS version 12.0 were used for the statistical comparison between materials at $95 \%$ confidence level.

\section{RESULTS}

Eclipse $^{\circledR}$ baseplate showed the highest impact strength $\left(2.73 \mathrm{~kJ} / \mathrm{m}^{2} \pm 0.54\right)$ followed by Meliodent ${ }^{\circledR}$ Rapid Repair $\left(2.50 \mathrm{~kJ} / \mathrm{m}^{2} \pm 0.65\right)$, Meliodent ${ }^{\circledR}$ Heat Cure $\left(1.96 \mathrm{~kJ} / \mathrm{m}^{2} \pm 0.42\right)$ and the Experimental PU exhibited the lowest impact strength $\left(1.04 \mathrm{~kJ} / \mathrm{m}^{2} \pm\right.$ 0.29) as illustrated in Figure 1.

Data exploration showed acceptable skewness and kurtosis values. The box plot (Figure 2) indicated two outliers, one each for the Meliodent ${ }^{\circledR}$ Rapid Repair group and the Meliodent ${ }^{\circledR}$ Heat Cure that contributed to the slightly high skewness and kurtosis values for the two groups when compared the Eclipse ${ }^{\circledR}$ and the Experimental PU groups. Levene's test revealed that homogeneity of variance across all groups can be assumed, $\mathrm{p}=0.159$.

One-way ANOVA showed that there is a significant interaction between all materials tested, $\mathrm{p}<.05$ (Table 2). Tukey HSD multiple comparison test showed that Experimental PU exhibited significantly lower impact strength compared to other materials. Meliodent ${ }^{\circledR}$ Rapid Repair was not significant different from Meliodent ${ }^{\circledR}$ Heat Cure and Eclipse $^{\circledR}$ base plate resin.

\section{DISCUSSION}

This study was principally aimed at comparing the impact strength of a newly developed experimental polyurethane-based polymer (Experimental PU) with a heat-cured acrylic resin, self-cured acrylic resin and, Eclipse ${ }^{\circledR}$ baseplate resin which is a urethane based oligomer. It was important to determine the impact strength of this experimental polymer material as the data can be used as a reference for further refinement of this polymer material to be used as polymer for denture fabrication.

Fracture of dentures is common and frequently due to forces from accidentally dropping the denture during cleaning (22). A review of the literature revealed that there were variations in specimen preparation, its dimensions, presence or absence of notch, and method utilized for testing the impact strength. In this study, Charpy Impact test was chosen due the availability of the testing equipment and it has been used other researchers $(23,24)$. This will also facilitate the comparison of test results to

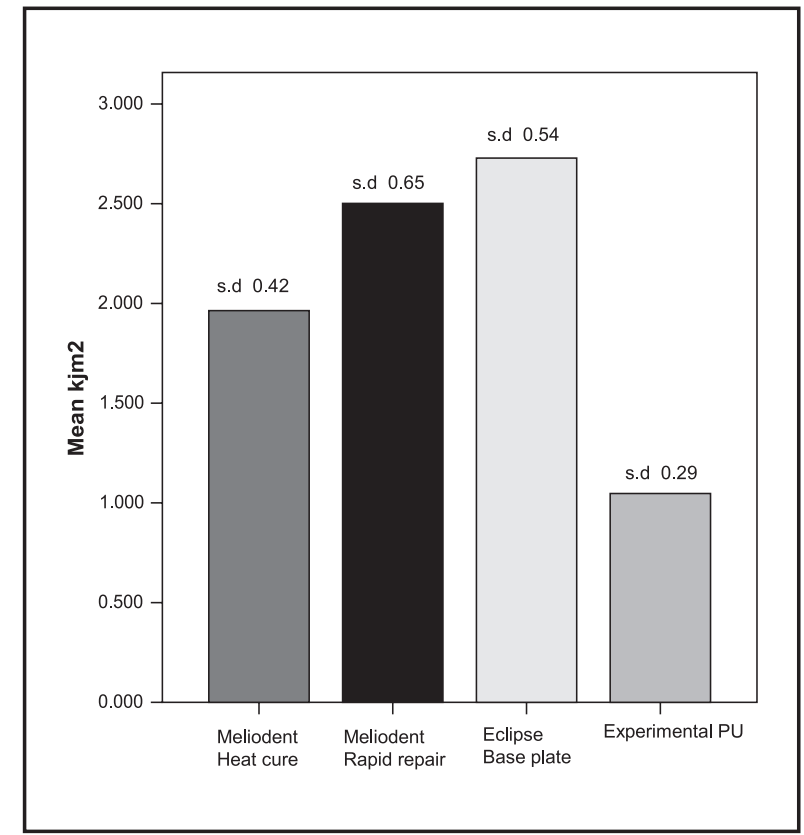

Figure 1: Mean impact strength of materials tested with standard deviation.

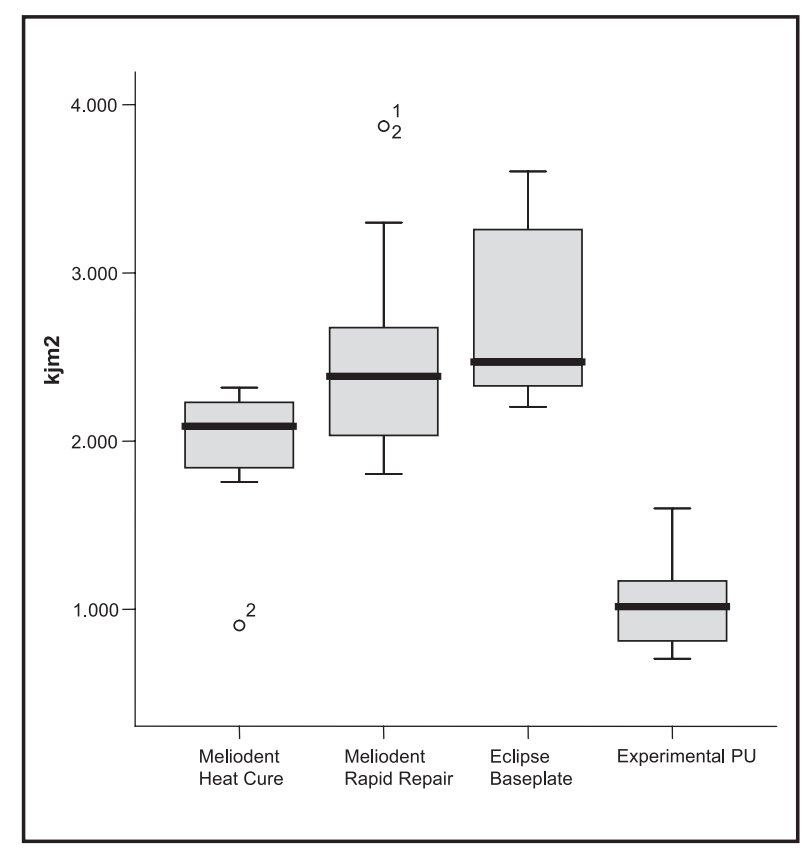

Figure 2: Box plot.

Table 2. Summary of One-way ANOVA showing significant interaction between groups

kjm2

\begin{tabular}{lrrrrr}
\hline & $\begin{array}{c}\text { Sum of } \\
\text { Squares }\end{array}$ & df & $\begin{array}{c}\text { Mean } \\
\text { Square }\end{array}$ & F & Sig. \\
\hline Between Groups & 16.777 & 3 & 5.592 & 22.931 & .000 \\
Within Groups & 8.780 & 36 & .244 & & \\
Total & 25.556 & 39 & & & \\
\hline
\end{tabular}


previous studies to some extend as there may be variations in the method of specimen preparations.

Specimens were prepared in accordance to that described by ISO 1567: 1999, which was also used by Rahammeh et al. in 2003 (16). The dental flasks used in the specimen fabrication were less than $80 \mathrm{~mm}$ hence the most recent ISO 1567 which was amended in year 2000 was not used where the recommended specimen dimension was $80 \mathrm{x} 10 \mathrm{x}$ $4 \mathrm{~mm}$. Dissimilar specimen dimension does not exhibit a wide variation in impact strength results as shown by Zappini et al.(23) and Rahammeh et al.(16) who reported that the impact strength data of heat-curedd PMMA and was $\left(1.36 \mathrm{~kJ} / \mathrm{m}^{2} \pm 0.03\right)$ and $\left(1.61 \mathrm{~kJ} / \mathrm{m}^{2} \pm 0.44\right)$ respectively.

In this study, a V-shaped notch was incorporated in the specimens in order to stimulate the oral condition where notches are present at the frenal area and to resemble scratches that can be found on the surfaces of dentures. These are the common stress concentrated areas which may reduce the strength of a denture. The presence of a notch will also ensure that the test specimens break at the same point during testing. Robinson \& McCabe (25) found that there was a significant reduction of impact resistance when specimens have surface defects. Their finding was later substantiated by Vallittu et al. (18). Memon et al. (26) investigated the impact strength of unnotched specimens made from Meliodent ${ }^{\circledR}$ Heat Cure denture base material of similar dimensions used in this study. They reported an impact strength value of $13.9 \mathrm{~kJ} / \mathrm{m}^{2}$ compared to that of $1.96 \mathrm{~kJ} / \mathrm{m}^{2}$ obtained in this study, when notched specimens were used.

The literature revealed that there are various ways of incorporating a notch on the specimens. Notches can be made either by machining after specimens preparation, moulding the notch during specimen preparation, or forcing a blade into the surface on the test specimens. The notch can either be blunt or sharp. In this study, a V-shaped notch was made as suggested by Rahammeh et al. (16). This method was chosen so that comparison can be made and it has been found to produce a consistent depth notch when compared to moulding or blade technique. Difficulty in obtaining consistent notch's depth was encountered during this study as a manually operated machine was used. This resulted in notches of various depths, $0.8 \mathrm{~mm} \pm 0.01$. This variation may have been reflected in the relatively high standard deviation obtained in this study. However, the result of this study was comparable to the findings of Zappini et al. (23). They reported that the impact strength of heat-cured PMMA denture base polymers tested in their study was $1.36 \mathrm{~kJ} / \mathrm{m}^{2} \pm 0.09$ for Probase Hot (Ivoclar Vivadent, Liechtenstein) and $1.36 \mathrm{~kJ} / \mathrm{m}^{2} \pm 0.03$ for Major Base 2 (Major, Moncalieri, Italy). While the impact strength of the heat-cured PMMA used in this present study was $1.96 \mathrm{~kJ} / \mathrm{m}^{2} \pm 0.42$. The differences in the results obtained are likely to be due to the following; firstly, the PMMA polymers are from different manufacturers thus employing different polymerization cycles for specimen preparation. Secondly, the duration for specimen storage may also contribute to this difference in results as a period of $48 \pm 2$ hours was used in this study while Zappini et al. (23) stored their specimens for 7 days.

One would expect the impact strength of self cured PMMA to be lower compared to heat-cured PMMA as it has always been assumed that self cured PMMA contained more residual monomer than heat-cured PMMA $(9,26)$. When immersed in water, residual monomer will leached out causing plasticizing effect thus lowering the impact strength. The results of this study contradict this assumption. In this study, the impact strength of self cured PMMA was higher compared to that of heat-cured PMMA. This was also observed by Vallittu \& Narva (13) where unnotched specimens were tested. Lim et al. (27) showed that the water absorption of the same self cured PMMA (Meliodent ${ }^{\circledR}$ Rapid Repair) was higher than that of the heat-cured counterpart. The actual amount of residual monomer leached from both heat and self cured PMMA has to be investigated in order to explain this observation.

Urethane oligomer, Eclipse ${ }^{\circledR}$ baseplate resin exhibited the highest impact strength in this study. It is not possible to compare Eclipse ${ }^{\circledR}$ baseplate resin with other urethane base polymers as there was no published work on impact strength of Eclipse ${ }^{\circledR}$ base plate resin. Memon et al.(26) reported that Microbase $^{\circledR}$ (Dentsply, DeTrey, Germany) which was also a polyurethane polymer base have the impact strength of $6.3 \mathrm{~kJ} / \mathrm{m}^{2} \pm 0.3$, however the results cannot be directly compared to this study as unnotched specimens were used. The high impact strength of Eclipse $^{\circledR}$ obtained in this study was probably due to it being light activated and higher degree of conversion. Eclipse ${ }^{\circledR}$ was also presented in a paste form which will minimize the presence of air bubbles and porosity which can lead to cracks propagation and low impact strength. Pfeiffer and Rosenbauer (28) quantified the amount of residual monomer using gas chromatography and reported that no residual monomer was detected for Microbase ${ }^{\circledR}$ (Dentsply, DeTrey, Germany), a polyurethane-based polymer. They attributed this finding to the Microbase ${ }^{\circledR}$ formulation and no other explanation was presented. Since Eclipse ${ }^{\circledR}$ is a urethane dimethacrylate-based oligomer, it is likely to have no or low residual monomer content thus contributing to its high impact strength value. However, this assumption has to be further investigated.

No significant difference was found between the impact strength of Eclipse ${ }^{\circledR}$ baseplate resin and selfcured PMMA. This may be explained by the amount of residual monomer, however as stated before the 
amount of residual monomer in these resin polymer need to be quantified before further postulation can be made.

Gan et al. (20) extracted polyol from palm oil and patented the resulting polyurethane-based polymers. These polymers may have suitable application in clinical dentistry. The experimental polyurethane polymer contained a lot of air bubbles as the isocyanate catalyst used was reactive to the atmospheric moisture during processing. Moisture react with the isocyanate to form carbamic acid which is unstable in the exothermic state which then decomposes to form an amine and carbon dioxide in the form of gas which produces foamy materials. This results in materials with high porosity. Therefore it was not surprising that the impact strength of this experimental polyurethane-based polymer was significantly lower compared to all materials tested. However, these results provide a valuable data in an effort to further refine this experimental material. The processing procedures need to be optimized where an alternative catalyst and a more controlled processing environment has to be employed. Fillers and fibers can also be added in this basic experimental polymer in order to enhance its impact strength and other mechanical properties.

\section{CONCLUSIONS}

Within the limitation of this study, the following conclusion can be drawn:

1. Eclipse $^{\circledR}$ baseplate resin exhibited the highest impact strength among all materials tested; however it was not significantly different from Meliodent ${ }^{\circledR}$ Rapid Repair.

2. The experimental polyurethane-based polymer (Experimental PU) showed a significantly lower impact strength compared to all other materials tested.

\section{REFERENCES}

1. Diwan R. Materials Prescribed in the Management of Edentulous Patients. In: Zarb G, Bolander CL.(ed): Prosthodontic Treatment for Edentulous Patients. ed 12. St. Louis, C.V. Mosby, 2004: 190-207.

2. Boone ME. New materials and techniques in Prosthodontics. Dent Clin North Am 1983; 27 : 793-803.

3. Anusavice K (ed). Phillips' Science of Dental Materials, $10^{\text {the }}$ d., W.B. Saunders, 1996.
4. Phoenix RD. Denture Base Materials. Dent Clin North Am, 1996; 40: 113-20.

5. Ferracane JL. Materials in Dentistry, Principles and Application. $2^{\text {nd }}$ ed. Lippincott. Williams and Wilkins. 2001: 255-80.

6. Faot F, Costa MA, Del Bel Cury AA, Rodrigues Garcia RCM. Impact strength and fracture morphology of denture acrylic resins. J Prosthet Dent 2006; 96: 367-73.

7. Phoenix RD, Mansueto MA, Ackerman NA, Jones RE. Evaluation of mechanical and thermal properties of commonly used denture base resins. J Prosthodont 2004; 13: 17-27.

8. Uzun G, Hersek N, Tincer T. Effect of five woven fiber reinforcements on the impact and transverse strength of a denture base resin. $\mathbf{J}$ Prosthet Dent 1999; 81: 6616-20.

9. Johnston EP, Nicholls JI, Smith DE. Flexural fatigue of 10 commonly used denture base resins. J Prosthet Dent 1981; 46: 478-83.

10. Douglas WH and Bates JF. The determination of residual monomer in polymethyl methacrylate denture base resins. J Mater Sci 1978; 13: 26004.

11. Vilaplana J, Romaguera $\mathrm{C}$ and Cornellana F. Contact dermatitis and adverse oral mucous membrane reactions related to the use of dental prostheses. Contact Dermatitis. 1994; 30: 80-4.

12. Alanko K, Kanerva L, Jolanki R, Kannas L and Estlander T. Oral mucosal diseases investigated by patch testing with dental screening series. Contact Dermatitis 1996; 34: 263-7.

13. Kanerva L, Jolanki R and Estlander T. 10 years of patch testing with the (meth)acrylate series. Contact Dermatitis 1997; 37: 255-8.

14. Jagger D, Harrison A, Vowks R. and Jagger R. The effect of the addition of surface treated chopped and continuous polymethymetacrylate fibres on the properties of acrylic resin. J Oral Rehabil 2001; 28: 865-72.

15. Kanie T, Fujii K, Arikawa H, Inoue K. Flexural properties and impact strength of denture base polymer reinforced with woven glass fibers. Dent. Mater. 2000; 16: 150-8. 
16. Rahammeh A, Jagger DC, Harrison A. The effect of the addition of different fibers on the transverse and impact strength of acrylic resin denture base materials. Eur. J. Prostho. Rest. Dent. 2003; 22: 75-81.

17. Vallittu PK, Narva K. Impact strength of modified continuous glass fiber polymethylmetacrylate. Int. J. Prosthodontic 1997; 10: 142-8.

18. Vallittu PK, Voltkova H, Lassila VP. Impact strength of denture polymethylmethacrylate reinforced with continuous glass fiber and metal wire. Acta Odont. Scand. 1995; 53: 392-6.

19. Randall. The Polyurethanes Book. Wiley 2002.

20. Gan SN. A process for producing polyol and polyurethane adhesive. 2004. Malaysia Patent Application No: P120042859.

21. Lamba NMK, Woodhouse KA, Cooper SL. Polyurethanes in Biomedical Application. CRC Press LLC. 1998.

22. Darbar UR, Hugget R, Harrison A. Denture fracure - a survey. BrDent J 1994; 176: 342-5.
23. Zappini G, Kammann A. and Wacther W. Comparison of fracture test of denture materials. J Prosthet Dent 2003; 6: 578-85.

24. Price CA. The effect of cross linking agent on the impact resistance of linear polymethylmethacrylate denture base polymer. J. Dent. Res. 1986; 65: 987-92.

25. Robinson JG, McCabe JF. Impact strength of acrylic resin denture base with surface defect. Dent. Mater. 1993; 9: 355-60.

26. Memon MS, Yunus N, Razak AA. Some mechanical properties of highly cross linked, microwave polymerized, injection mould denture base polymer. Int J Prosthodont 2001; 14: 2148.

27. Lim MC, Khor ST, Abu Kasim NH. Water absorption of an experimental polyurethanebased polymer derived from palm oil. Elective Project Report, Dental Faculty, University of Malaya 2006.

28. Pfeiffer P and Rosenbauer E. Residual methyl methacrylate monomer, water sorption, and water solubility of hypoallergenic denture base materials. J Prosthet Dent, 2004; 92 (1): 72-8. 